\title{
The study of college physical education reform under the field of lifelong sports in Hunan Province
}

\author{
Yuanchao Zhou \\ Hunan University of Science and Technology, Xiangtan, Hunan(411201) , \\ Xiangtan,China. \\ 664257664@qq.com
}

\begin{abstract}
School physical education was an important part of the lifelong sports, and there were vital influence of the concept of lifelong sports on the education teaching reform of school physical education. It was the real need of human society on the concept of lifetime sports which was put forward by the experts, and school physical education as the basis of lifetime sports, which was essential to cultivate students' awareness of lifelong sports with lifetime sports skills. Hence, in this paper, the relationship of lifelong sports and college physical education were explored using the scientific research mothods of literature material anlysis, questionnaire surveying and statistics, and the current situations of physical education teaching in colleges and universities were also investigated in hunan province, so as to give some advices for the reform of college physical education, and to lay a foundation for the implementation of lifetime sports.
\end{abstract}

Keywords-lifelong sports; college physical education ; physical education reform

\section{INTRODUCTION}

College physical education was the important process of the sports practice and physical education teaching, and also, it was the basic stages of lifelong exercise. College physical education teaching was the most standarization and systematization stage to the students. it was the most important period to cultivate individual lifetime sports consciousness and improve the ability of lifelong sports and form lifetime sports concept. So the college physical education teaching had an important status to cultivate the students' lifetime sports concept. Colleges and universities were the base of cultivating the talents, and physical education teaching was the basis of training physical fitness[1]. A qualified personnel should not only have profound professional knowledge, also must have a healthy body. College physical education teaching was not only a simple for students to have PE lessons, the most important was to let students understand sports knowledge, master certain fitness method, and have the physical exercise habit. Colleges and universities physical education teaching should be timely to strengthen students' subject consciousness, improve the ability of independent exercise, strengthen the concept of lifetime sports, master the knowledge and the correct method of exercise.

The students in colleges and universities were in the period of normal development, and they were the most precious and were the most distinctive golden era in life. In the stage of vigor and vitality[2], the college students would build their own concept on physical exercise if the sports teachers can imbue with practical teaching contents, impart systematically the method of scientific exercise combined with the good exercise equipment, environment and the atmosphere of physical exercise.

\section{OBJECTS AND METHODS}

\section{A. Objects}

In order to more accurate understanding the physical education teaching situation in colleges and universities of hunan province, 100 of sports teachers and 200 of college and university students were investigated from eight college and university, including Hunan University, Centre southern University, college of Changsha, Hunan normal university, Xiangtan university, Huan university of scicence \& technology, Hunan engering college and Hunan industrial university.

\section{B. Methods \\ 1) Literature analysis}

According to the keywords of physical education teaching, teaching structure, the universities sports teaching, looking at the Chinese knowledge network (www.cnki.net), Chinese education network (www.chinaedu.edu.cn), a series of literatures were obtained from the core journals and academic papers, it was provided us the new thought and methods for the researches. 


\section{2) Questionnair survey}

According to the literature analysis, on the basis of the status quo and the current research hot spot, the questionnaire for this study was built. Then, by consulting relevant experts and scholars to revise and confirm the contents of the questionnaire. In this study, 100 of questionnair for the sports teachers and 200 of questinnair for the college students were issued, and 98 $(98 \%)$ and 195 (97.5\%) of them were recovered respectively. The valid questionnaires were 90 (95\%) and $188(94 \%)$ respective. Before issuing the questionnair, 10 experts ,3 of them were professor, 2 of them were vice profess or and 5 of the m were administor of physical education) were consulted to assess the relability and validity of the 2 questionnairs. $90 \%$ of experts confirmed that the questionnair for teachers was valid, and $92 \%$ of experts confirmed that the questionnair for students was valid. The relability was checked according to the "test-retest relability", the correlation coefficient of 2 times of tests were $R=0.825$, $\mathrm{P}<0.05$.

\section{3) Statistics}

The SPSS 17.0 edtion was used to statistics.

\section{III. RESULTS AND ANALYSIS}

A. The current situation of physical education teaching in colleges and universities of hunan province under the field of lifetime sports
Physical education teaching guidance in the colleges and universities was the core of the basic views and understanding to direct the physical education teaching and activities. It reflects the period from the perspective of sports community in colleges and universities sports teaching to cultivate the talent requirements. With the development of physical education teaching reform in colleges and universities, the goal and the function of physical education teaching was heading for diversified. The phyical education teaching in the colleges and universities of hunan province was the status of variety of teaching ideas, each of them were very close but not the same. There were differences between each other, and each kind of teaching thought had its era background and historical origin. With the development of the national fitness campaign, the physical education teaching was puts forward the new requirements:in colleges and universities: lifetime sports was as the teaching guiding thought, strengthen their physical fitness was as the essence. In the sports teaching either consciously or unconsciously use some kind of guiding ideology, should practice of physical education and knowledge skills, the cultivation of the ability to balance up to promote the all-round development of students. Through the new "national ordinary university sports curriculum teaching instruction summary" the guiding ideology of education idea was: healthy the first, quality education, lifelong sports ideology. But in the fact, there were $51.8 \%$ of college students not ware of the lifelong sports concept (table 1), and they can not understand the relationship of the health exercise and the future life.

TABLE I. THE SURVEY OF THE LIFELONG SPORTS FOR THE STUDENTS

\begin{tabular}{|c|c|c|c|}
\hline & Understand well & Understand & Not understand \\
\hline numbers & 23 & 69 & 96 \\
\hline rates & $20.12 \%$ & $36.70 \%$ & $51.08 \%$ \\
\hline
\end{tabular}

B. The analysis of physical education teaching mode

in the colleges and universities of Hunan province

According to investigation and survey, it was found that colleges and universities of Hunan province, the physical education teaching mode can be divided into three types. The first was compulsory: physical education learning content per semester was uniformed by the colleges and universities, it paid more attention to the student skills. The second was a compulsory add up to elective: physical education learning content in the grade one was uniformed and compulsory course, students can choose the learning coures according to their interest in grade two, it can choose their sports contents according to their own interests and hobbies, so as to stimulate students' interest in learning. The third was special elective course in grade one, and then the sports club teaching in grade two, it was benifit to exert students' subjective initiative, and to students' special skills and interests. Along with the advancement of teaching reform, the physical education teaching mode was varied from the original single model to multiple modes, and colleges and universities can be combination of these different teaching modes according to their own teaching conditions, so as to stimulate students' exercise interest and cultivate students' healthy consciousness of lifetime sports.

\section{The analysis of physical education teaching contents}

According to table 2, it was found that the teaching contents were selected mainly as the items for the examination and the equipments and teaching conditions, it was $30.0 \%$ and $46.7 \%$ respective, and the teaching contents selected according to the students' interests, physical and mental abilities and novel exercise items 
were only the $5.6 \%, 14.4 \%$ and $3.3 \%$ respective. It was shown that the teaching contents selected relay on the concept of lifelong sports were relative lower.

TABLE II. THE SURVEY OF PHYSICAL EDUCATION TEACHING CONTENTS

\begin{tabular}{l|c|c}
\multicolumn{1}{c|}{ Teaching contents } & Numbers & Rate \\
\hline Interest for students & 13 & $14.4 \%$ \\
\hline Items for the examination & 27 & $30.0 \%$ \\
\hline Alteration for the students demands & 5 & $5.6 \%$ \\
\hline Items with novelty & 3 & $3.3 \%$ \\
\hline Items for the equipments and conditions & 42 & $46.7 \%$ \\
\hline
\end{tabular}

D. The analysis of physical education teaching method in colleges and universities of hunan province

With the deepening of education reform, the diversification of teaching methods for the sports teaching provides a large teaching methods which can be used for reference. Research new discoveries in the field of pedagogy, psychology and other disciplines, combined with information technology applied in the field of teaching, which had physical education teaching methods tend to be modernization, democratization, personality. As seen from table 3,100\% of the teachers in teaching put to use of the methods of explanation and demonstration combination with practice, and $84.4 \%$ of the teachers had the use of assemble and disassemble teaching method, and $45.5 \%$ of the teachers were used to games and match teaching method. The teaching method of reasonable selection and use was very important in the physical education teaching in colleges and universities to improve the teaching quality, or to develop students' creative ability and innovative consciousness, and even to improve sports facilities. Adopting the teaching methods of physical education teachers in hunan province colleges and universities still adopt more ancient, to mobilize the students' interest in sports teaching method to use less, is not conducive to students' cons ciousness of lifetime sports training.

TABLE III. THE SURVEY OF PHYSICAL EDUCATION TEACHING METHODS

\begin{tabular}{c|c|c}
\hline Teaching method & Number & Rate \\
\hline Explainning and demonstrating & 90 & $84.4 \%$ \\
\hline Assemble and disassemble & 76 & $88.8 \%$ \\
\hline Repeatedly exercise & 80 & $45.5 \%$ \\
\hline Game and match & 41 & $27.7 \%$ \\
\hline Multimedia teaching & 25 & $14.4 \%$ \\
\hline
\end{tabular}

E. The analysis of physical education teaching assessment in colleges and universities of hunan province

It can be seen from table 4, as sessment of sports in hunan province colleges and universities exist two main problems [3]: the one was to master the theoretical knowledge and application and the performance of the students' subjective initiative in the learning process not well reflected in the examination, the examination of the guidance, the teachers and students to the learning process of the sports curriculum ignored, pay attention to the results evaluation, to pass the examination qualified as the main goal. Therefore, formed a "want me to exercise" in sports teaching and lifelong sports the contradiction between "I want to exercise" "second, ignoring the individual differences, can be seen from table 4, technical standards, technical evaluation and score of physical quality accounts for some $80 \%$ of the assessment results, the two parts of achievement and the students' sports foundation and the genetic factors have a 
close relationship of the body, and sports course and other courses of a major difference is the students in addition to its own efforts, by genetic factors (height, weight, etc.) is very big, the influence of individual differences is greater than the individual differences of other course[4]. Therefore, assessment should attach importance to students' individual differences, in order to improve each student's active, creative and self-confidence, such ability, with the purpose of the new physical education curriculum corresponds to a task.

TABLE IV. THE SURVEY PHYSICAL EDUCATION TEACHING ASSESSMENT

\begin{tabular}{c|c|c|c|c}
\hline Contents & Basic knowledge & Skill & Physical fitness & Attitude \\
\hline Rate & $5-10 \%$ & $40-80 \%$ & $20-40 \%$ & $10-20 \%$ \\
\hline Reqirments & $\begin{array}{c}\text { Writ unifiedly } \\
\text { examination }\end{array}$ & Unified special items & $\begin{array}{c}\text { Combinationwith } \\
\text { special items }\end{array}$ & $\begin{array}{c}\text { Perfermance in class } \\
\text { and attendance rate }\end{array}$ \\
\hline
\end{tabular}

To solve the problems of the teaching contents

IV. THE COUNTERPLAN OF PHYSICAL EDUCATION

TEACHING REFORM AND THE DEVELOPMENT OF

COLLEGES AND UNIVERSITIES UNDER THE FIELD OF

\section{LIFELONG SPORTS IN HUNAN PROVINCE}

A. Change the teaching thought, carry out the connotation of quality education, establish the guiding ideology of "lifetime sports"

First of all, school education should set the guiding ideology of "lifetime sports"[5]. The guiding ideology was the soul of education. The administors of colleges and universities in charge of physical education teaching and the teachers should set up the guiding ideology of the lifelong sports. Second, lead teachers to explore, the lifelong physical education guiding ideology into the teaching process, constantly create has the time feeling, suitable for students of practical, can fully mobilize students' creative study method of teaching.[6] Practice how teachers should put by the principal role of the teacher to the students how to learn the barycenter offset, fully respect students, care for students, pay attention to individual mental development and the cultivation of creative ability[8]. To give students more free activities and space, the lifetime earnings during the period of school sports benefit and students, the combination of the acceptance and the pursuit of health into the student individual intrinsic demand, as the body and mind coordinated development, natural process, [7] the pursuit of pleasure, to improve students' ability of individuals to maintain health, strengthen the awareness of lifelong sports, satisfy self emotional experience, to adapt to changes in the environment and the development of the society, raise the health level of the whole nation.

B. The reform of teaching content, play the dominant role of students which were tend to form the funcation of directing to competitive sports, rather than to lively happy sports or lifelong sports, it should reform the teaching material, so as to play the dominant role of students[8,9]. Tha pathway of reform the teaching material was to meet the damand of adapting to the needs of the development of student's body and mind. The teaching material contained the different contents of competitive sports, happy sports, lifelong sports. It would make the students give play to the dominant role in class, so as to improve the students' learning attitude and behavior.

\section{Lifetime sports thought as the basis of physical education teaching evaluation standard}

The guiding ideology of lifelong sports was the basis of evaluation the teaching contents of physical education. Lifelong sports under the idea of evaluating the essence was how to change people's values, to the value judgment standard for adjustment and change of school sports. [10] the introduction of students' sports attitude, interest, students lifelong sports consciousness, habit and ability evaluation. Pay attention to process evaluation and diagnostic evaluation, the combination of formative assessment and summative as sessment. In the practice of teaching, process evaluation and diagnostic evaluation were a process for students in physical education teaching activity in the learning effect evaluation, and formative assessment and summative assessment were learning evaluation for students as a whole. The combination of the four evaluation was help for paying attention to students' learning process, exploring process and efforting process. On the other hand, it can also explain the learning effect to the student. And also, this kind of assessment mechanisms was in favor of giving an objective estimation in the learning attitude, the value of longlife sports and scientific exploring spirits. 


\section{ACKNOWLEDGMENT}

The stage results of the twelve-five subject of Hunan Education

Planning, subjectnumber(XJK012BTM004)

\section{REFERENCES}

[1] CHEN Qi, Consideration on Reform and Development of Our School Physical Education from the Point of Life Education Thought [J], sports science, 2009:(1):40-43.

[2] FUGuang-lei,AboutLong-lifeSportsinPETeachinginCollege [J], Journal of Nanjing Institute of Physical Education. 2013:(6):101-102.

[3] YU Qi-guang. The research of college physical education and lilelong sports [J], Journal of Anhui University of Science and Technology (social edtion). 2012(2):86-88.
[4] YAO Wei-jun. The relationship of national fitnenss and lifelong sports from the view of college physical education [J] Hubei sports technology.2012(1):117-118.

[5] MENG Wuryun. School education and lifelong sports[J]. Journal of textile engineering institute, 2010, 7:16-18.

[6] Li Yunlin, "Environmental Construction of Modern Educational Technology of School", Research on Audio-visual Education, vol.35,pp.56-59, 2008.

[7] Wu Yongzhi, "Classification, Configuration and Characteristics of Multimedia Teaching Environment", Research on Audio-visual Education, vol.41,pp.39-41,2010.

[8] Wang Daguang, T anqu, "Research on Environmental Construction of CAI Teaching of Multimedia in Colleges and Universities", Higher Education Forum, pp.49-51,2014(6).

[9] Wu Yi, "Exploration and Practice of Integrated Digital Learning Environment in 21 Century ", Research on Audio-visual Education, vol.54,pp85-86,2012.

[10] Jiang Sizheng, "On Modern Education Technology of Colleges and Universities in the New Era ", Research on China Higher Education , pp.64-65,2001 (8). 